Madrygal. Revista de Estudios Gallegos

ISSN: 1138-9664

\title{
Razón biográfica e traballo de arquivo no estudo de Rosalía de Castro ${ }^{1}$
}

María do Cebreiro Rábade Villar

As investigacións da profesora María Victoria Álvarez Ruiz de Ojeda constitúen a plenitude e ilustración dos estudos rosalianos do noso tempo, especialmente no ámbito da historia literaria e da exhumación documental. Somos moitas as persoas que agradecemos o feito de que eses traballos existan na forma exacta na que existen. Os seus artigos combinan dun xeito pouco usual a erudición e o sentido crítico. Deste xeito, ao tempo que avanzan datos sempre pertinentes, van construíndo unha reflexión de carácter progresivo sobre a historia do rosalianismo. Case como nunha declaración de intencións da súa traxectoria posterior, nun dos seus primeiros artigos a propia investigadora referíase a este dobre proceso: "O historiador sabe que é difícil facer falar as fontes, pero iso non o exime de buscalas e de interrogalas, como non nos eximimos nin nos eximiremos nós de revisar o corpo de opinións que teceu en torno a Rosalía o século que agora morre" (1999a: 48).

O obxectivo das seguintes liñas é tentar precisar cales son as razóns que fan dos artigos de María Victoria Ruiz de Ojeda un acontecemento extraordinario no seu contexto de produción intelectual, ao punto de que podería afirmarse que deron lugar a unha viraxe copernicana nas investigacións sobre a vida e a obra de Rosalía de Castro. Para iso detereime sobre todo nos factores disciplinares e de método. Se atendemos ás razóns disciplinares, o primeiro que cumpriría observar é a orientación histórica da súa investigación. Desde os primeiros traballos de Carballo Calero aos traballos de
Bouza-Brey Trillo poucos foron os chamados a retomar en Galicia a nobre tarefa de reconstruír con solvencia e ponderación as fontes que fan posible un maior coñecemento da escritora. Unha muller que, no que atinxe a determinados feitos e circunstancias, resulta aínda unha verdadeira descoñecida.

Se cavilamos no método, cumpriría salientar a vocación fondamente empírica das investigacións de Ruiz de Ojeda. Non foi usual, na crítica rosaliana, que os estudos empíricos se impuxesen aos de orientación interpretativa. Nin o foi no pasado nin o é no presente, onde, consciente ou inconscientemente a miúdo procuramos unha Rosalía de Castro que encaixe en parámetros e modelos predeterminados, cando non en proxeccións ou mesmo en desexos. $\mathrm{O}$ interesante é que, cando menos en Galicia, esta estratexia de lectura máis baseada nos valores que nos datos deuse con semellante incidencia en persoas situadas en posicións intelectuais e ideolóxicas moi afastadas entre si.

A causa disto non debe situarse unicamente na consabida tendencia humana á mitificación, aínda que -debido ao seu papel fundacional na cultura galega contemporánea- a tendencia resultase moi acusada no caso de Rosalía de Castro. A obliteración do método empírico débese, con frecuencia, a unha razón máis prosaica. Cómpre recoñecer que actividades tan nobres como as de especular e tecer hipóteses, por difíciles que poidan chegar a ser, son menos fatigosas que a de lixar as mans na procura dos documentos (Álvarez Ruiz de Ojeda e Vilavedra 2007: 99). Pero os 
historiadores, en xeral, traballan situándose á escoita. Son investigadores sensibles ao xeito preciso que a verdade, sempre fuxidía, escolle para se revelar. E saben que unha forma do que chamamos verdade só se revela no traballo de arquivo. Nada máis lonxe da miña intención que desestimar a hermenéutica como chave de acceso ao estudo dos escritores. Con todo, no caso da autora galega, mesmo os traballos que antepoñen a dimensión teórica á histórica contraen obrigas impagables coas investigacións de carácter empírico e documental, e os artigos da investigadora deseñan un programa de investigación onde, de xeito admirable, se fai realidade a vella aspiración filolóxica que consiste en conciliar a procura dos datos coa súa apropiada eséxese.

Álvarez Ruiz de Ojeda comezou a súa traxectoria académica cun traballo sobre a lingua de Rosalía de Castro, onde amosaba xa a súa capacidade para localizar aqueles aspectos que, dentro do inxente corpus da crítica rosaliá, eran merecentes dunha maior ou mellor atención. Na mesa redonda sobre os Usos da lingua en Rosalía de Castro, que tivo lugar o pasado 28 de febreiro, a profesora da Universidade da Coruña Goretti Sanmartín Rei afirmaba a relativa desatención da que fora obxecto tradicionalmente a investigación lingüística dentro do rosalianismo. Podemos afirmar, xa que logo, que só un ano despois do Congreso Internacional sobre a obra de Rosalía de Castro e o seu tempo, Álvarez Ruiz de Ojeda nacía para os estudos rosalianos como unha continuadora, pero tamén como unha descubridora. A súa memoria de licenciatura facía gala de dúas cualidades investigadoras que definen a totalidade do seu traballo e que non é doado ver comparecer de xeito simultáneo nunha soa persoa. Dunha banda, o coñecemento -tan rigoroso que diriamos case exhaustivo- da bibliografía precedente, que non é só unha cualidade intelectual, senón tamén unha cualidade ética: prestarlle a debida atención ao traballo dos que nos preceden e dos que nos rodean é sempre un xeito de honradez e de xenerosidade. En segundo lugar, o rigor crítico que a leva a desestimar determinadas solucións previas aínda que fosen consagradas pola tradición. Por iso se amosa especialmente cautelosa coas edicións modernas da obra poética rosaliá, pois constata que a miúdo deturpan as formas lingüísticas orixinais. Neste contexto, e precedida do epígrafe "Advertencia indispensable", Álvarez Ruiz de Ojeda escribe unha frase que debera tomarse como divisa de calquera traballo sobre a autora: "Queremos, xa desde aquí, advertir que en ningún momento corrixiremos a Rosalía, nin con Rosalía mesma" (1986: 12). Até onde eu sei, Ruiz de Ojeda non ten dado ao prelo traballos sobre a crítica textual da produción rosaliá, mais a ponderación que demostra esta obra prima -emblema daquilo que a crítica textual denomina iudicium - constitúe en boa medida un compendio das virtudes do traballo de edición. A miúdo se fala da ausencia dunha grande biografía de Rosalía de Castro como unha eiva dos estudos rosalianos, mais tal vez o verdadeiro déficit no caso de Rosalía é a ausencia dunha edición filolóxica actualizada da súa obra completa. Á marxe da relevancia social destas dúas tarefas e da súa prelación, probablemente non poderán darse de xeito cabal se as conceptualizamos como tarefas incomunicadas entre si, e coido que cómpre ler o traballo investigador de Ruiz de Ojeda como un longo refrendo desta hipótese.

En primeiro termo, os seus artigos deron respostas longamente procuradas a cuestións biográficas como as circunstancias do nacemento de Rosalía de Castro (Álvarez Ruiz de Ojeda 1999a) ou a identidade do crego Martínez Viojo, a través da exhumación de documentos tan relevantes como o seu testamento (2000b) ou, máis recentemente, a primeira mención documental que se conserva del como pai de Rosalía (2011a). De capital importancia foron asemade as súas investigacións sobre a familia dos Castro e a residencia da nai e mais a filla en Padrón desde a infancia de Rosalía (1999a), ou sobre a situación económica da escritora, da que dá testemuño a venda dunha parte da finca chamada "Balada", en Iria, que Rosalía herdara de súa nai (2002b). E moi suxestivo é o artigo que lle dedica á Rosalía de Castro actriz, con datos ben esclarecedores sobre as actividades artísticas e culturais do Liceo de la Juventud e sobre a temperá afección da autora pola escena teatral (2000a). Mais os artigos da investigadora esclarecen tamén aspectos controvertidos ou especialmente significativos da súa produción, tales como o epistolario inédito (1999b), a polémica arredor do desaparecido El codio (2008) ou a súa renuncia a seguir escribindo en lingua galega (1996). A través destes artigos a estudosa semella soster que, cando menos nunha escritora, o que chamamos vida sempre limita co que chamamos obra (Álvarez Ruiz de Ojeda e Vilavedra 2007).

De aí, entre outras cousas, o interese da autora por aclarar un aspecto moi importante na vida das persoas que escriben. Refírome ás 
amizades literarias. En datas recentes a investigadora botou luz sobre a amizade epistolar de Rosalía de Castro con Agna de Valldaura (Álvarez Ruiz de Ojeda 2010), transitando un camiño, o das relacións da escritora galega co campo literario catalán, que promete futuras descubertas. E outra tarefa en certa medida pendente, á que veu contribuíndo, sería a de explorar os círculos de sociabilidade de Rosalía de Castro, a súa formación intelectual ou o seu posicionamento nos debates ideolóxicos da época.

No que atinxe á cuestión da sociabilidade, resulta literalmente conmovedor un relatorio do ano 2007, presentado na Fundación Rosalía de Castro, no que Álvarez Ruiz de Ojeda demostra que Pilar Castro y Alván, destinataria dun fermoso poema rosaliano, era unha rapaciña, amiga da súa filla Alejandra, que morreu á idade de quince anos. Nun dos artigos que antes mencionei, a investigadora reproducía unha carta en lingua galega escrita polo chantre da catedral de Salamanca con ocasión da edición dos Cantares gallegos. O suxestivo, neste contexto, é que tanto Pilar Castro y Alván como Camilo Álvarez de Castro figuran nas dedicatorias de dous poemas rosalianos.

Álvarez Ruiz de Ojeda fai notar que as dedicatorias rosalianas son escasas, de aí que non sexa en absoluto irrelevante saber a quen e por que dedicou algúns poemas. Esta tarefa podería ser asimesmo iluminadora do vínculo entre Rosalía de Castro e a súa amiga galesa María Bertorini, antepasada dos Trulock de Iria, e á que a escritora lle dedica a súa impresionante "Oda ao xeneral Sir John Moore". E é moito, en suma, o que resta por saber sobre a sociabilidade feminina de Rosalía de Castro, desde esas amigas da infancia padronesa, ás que en Cantares gallegos evoca xogando canda ela no enxidiño, até as súas amigas da idade adulta, como a case descoñecida María Bertorini.

Como xa se apuntou, desde o comezo Álvarez Ruiz de Ojeda soubo simultanear o método empírico, rexido por un estilo investigador moi minucioso, co interese pola tradición do rosalianismo. Xa no ano 2002, ao tempo que se dedicaba ao achado, cotexo e edición de distintos documentos históricos, elaboraba unha summa de referencias (2002c) que viñan actualizar no seu día o valioso compendio de Pociña e López (1991-1993) e Pociña (2001). E deste interese pola tradición bibliográfica do rosalianismo seguirá dando testemuño de xeito ininterrompido até o presente. Así o demostra o seu interesante artigo sobre a influencia dos apuntamentos inéditos de Said de Armesto na biografía de González Besada, onde a autora repasa tamén criticamente a biografía de Uxío Carré Aldao e a súa dependencia do criterio murguiano (Álvarez Ruiz de Ojeda 2011a). Mais o seu proxecto de historiar a tradición biográfica de Rosalía alentaba xa na súa análise dun dos libros fanados de Álvaro Cunqueiro, "Amor i-estancia de Rosalía de Castro" (2002a).

A lección implícita destes dous últimos estudos pode enunciarse do seguinte xeito. Ningunha biografía de Rosalía de Castro será merecente de tal nome se non incorpora un traballo de revisión fonda da historia que rodea ás súas biografías anteriores, tanto das que existiron como das que, debido a distintos avatares, non chegaron a existir. Dicimos con frecuencia que non dispoñemos aínda dunha biografía canónica de Rosalía de Castro, mais se cadra deberiamos afirmar que carecemos dunha historia crítica das biografías de Rosalía de Castro. Tamén aquí o traballo de Ruiz de Ojeda ten un carácter pioneiro.

Vou tentar expandir argumentalmente agora o dito a propósito da relación entre vida e obra no caso dos escritores. Sendo a biografía un xeito de escritura sobre a vida, e sendo unha escritora a protagonista desa vida, unha biografía de Rosalía de Castro non pode darlle as costas a cuestións como as seguintes. En primeiro lugar, a reconstrución das súas bibliotecas, para o cal sería moi interesante reflexionar sobre o patrimonio familiar dos Castro, sobre o acceso ás fontes letradas na Compostela e no Madrid da segunda metade do XIX e sobre a análise sistemática do Fondo Gala-Murguía, actualmente custodiado na Real Academia Galega. A propia Álvarez Ruiz de Ojeda, citando un testemuño murguiano, apunta nun dos seus artigos que as influencias literarias máis claras da escritora serían poucas. Mais sabemos que o estudo da obra de Rosalía de Castro semella desmentir esta apreciación. Nun traballo de orientación erudita publicado hai agora un ano, Montserrat Ribao (2012) reconstruía a biblioteca de La hija del mar, na que é posible documentar a lectura miúda de moitos dos seus contemporáneos. Entre eles, Susana Cummins, autora norteamericana da época coa que Kathleen March (2012) ten comparado sagazmente a Rosalía.

E aquí é onde entra de novo o traballo de arquivo. Sexa na reconstrución das amizades persoais, sexa na reconstrución das amizades ou influencias literarias, non hai outro camiño máis fiable ca ese, aínda que os resultados que 
achegue rematen sendo incertos ou confusos. Podemos filosofar sobre a influencia de Bécquer sobre Rosalía ou a influencia de Rosalía sobre Bécquer, pero antes diso o que cumprirá mostrar documentalmente é se esa relación ten fundamento histórico e, no seu caso, cal. Nun dos artigos antes citados, Álvarez Ruiz de Ojeda (2011a) desennovela o nó rescatando testemuños de Carré, Murguía, González Besada e Said Armesto e amosando que, no caso de Rosalía de Castro, a veracidade e a autenticidade documental nunca chegan a confluír de todo.

Se tratamos da súa relación con Fernán Caballero, ou da súa admiración por George Sand, das que atopamos numerosos refrendos ao longo da súa obra, será útil contrastar estas mencións co que a mesma Rosalía de Castro escribe sobre elas no seu epistolario. Podemos especular sobre a súa adscrición ao socialismo utópico ou sobre a súa simpatía cara ao pensamento anarquista, pero estas cavilacións gañarán cando sexan substentadas en datos. Por exemplo, no feito de que a dedicatoria do Conto de Vidal a Roberto Robert (Cantares gallegos) remite á tradución que o escritor catalán fixera da obra de Proudhon Teoría da contribución (1862). Ou no feito de que o Fondo GalaMurguía documenta a recepción coetánea da Internacional Socialista, aínda que Rosalía de Castro nunca cite directamente a Marx.

Na primeira sesión deste Congreso, o profesor Barreiro Fernández (2013) sostivo que estabamos asistindo a unha rehabilitación do xénero histórico da biografía. Fronte ao paradigma estruturalista que se impuxera desde a segunda metade do século XX na historiografía literaria, hoxe estamos en disposición de recoñecer que as persoas teñen sempre unha marxe de axencialidade fronte ao signo dos tempos, que nunha vida cabe non só a asunción das condicións herdadas, senón tamén a súa transformación. Agardamos, xa que logo, con ansia por esa biografía de Rosalía de Castro, e esperamos que esa biografía a debuxe non só como unha persoa que viviu e que sentiu, senón tamén como unha persoa que escribiu e que pensou.

A través dun breve percorrido pola traxectoria investigadora de Ruiz de Ojeda, especialmente no que atinxe á orientación biográfica das investigacións sobre Rosalía de Castro, quixen mostrar o que ela nos aprende. Que non debera haber disociación real entre a investigación biográfica e histórica, nin entre a historia dos feitos e a dos documentos, nin entre a edición do total da obra e a interpretación do total da vida dunha escritora. A investigadora sabe que as casas non se fan polo tellado e vai colocando as pedras mestras do seu edificio, indicándonos con inacostumada humildade por onde cumpriría continuar. No entanto, outros e outras soñamos con poder dialogar de xeito minimamente digno cunha tarefa ao tempo tan modesta e monumental como a que ela sinala.

\section{Referencias bibliográficas}

Álvarez Ruiz de Ojeda, Victoria (1986): Algúns aspectos da lingua galega de Rosalía de Castro. Memoria de licenciatura inédita. Santiago de Compostela: Universidade de Santiago de Compostela.

(1996): “Sobre a 'demisión' de Rosalía: unha carta inédita de Manuel Murguia”, Grial. Revista galega de cultura 131, pp. 189-194.

_ (1997): "Un importante documento para a biografía de Rosalíade Castro", Grial. Revista galega de cultura 136, pp. 479-501.

_ (1999a): "Sobre as orixes de Rosalía de Castro: a inclusa de Santiago de Compostela e o caso de Josefa Laureana de Castro", A Trabe de Ouro 39, pp. 325-351.

— (1999b): "A primeira carta en prosa en galego moderno: Camilo Álvarez de Castro escribe a Rosalía sobre Cantares gallegos (1863)”. Grial. Revista galega de cultura 143, pp. 455-474.

(2000a): "Rosalía de Castro, actriz: noticias e documentos", Revista de estudios rosalianos 1, pp. $11-43$.

(2000b): "Documento para a biografía de Rosalía de Castro, testamento de José Martínez Viojo, presbítero", Grial. Revista galega de cultura 146, pp. 169-172.

(2002a): "Amor i-estancia de Rosalía de Castro: proxectos literarios xuvenís de Álvaro Cunqueiro",

Revista de estudios rosalianos 2, pp. 11-30.

- (2002b): "Un novo documento rosaliano: venda outorgada por Rosalía de Castro en 1866", Revista de estudios rosalianos 2, pp. 93-11.

(2002c): "Bibliografía rosaliana (1999-2002)", Revista de estudios rosalianos 2, pp. 179-235.

(2008): “Sobre 'El Codio' (1864), obra perdida de Rosalía de Castro", Revista de estudos rosalianos 3 , pp. 27-37. 
(2010): “Agna de Valldaura, unha amizade catalá de Rosalía de Castro”, Festa da palabra silenciada 26, pp. 56-59.

(2011a): "Víctor Said Armesto, Rosalía de Castro e Manuel Murguía (con Augusto González Besada ao fondo)", Revista de estudos rosalianos 4, pp. 15-126.

(2011b): "16 de xullo de 1885, primeira mención do capelán José Martínez como pai de Rosalía", Revista de estudos rosalianos 4, pp. 205-217.

Álvarez Ruiz de Ojeda, Victoria e Dolores Vilavedra (2007): “Que a morte me tarda: Rosalía, vida e literatura", en A. Blanco e M. Piñeiro (eds.), Diálogos na Casa de Rosalía II (decembro de 2005 - xuño de 2006). Santiago: Fundación Rosalía de Castro, pp. 99-113.

Barreiro Fernández, Xosé Ramón (2013): “A evolución política/intelectual do matrimonio Murguía-Castro, desde os anos sesenta aos anos oitenta do século XIX". Conferencia inaugural do Congreso Rosalía de Castro no século XXI. Unha nova ollada. Santiago de Compostela: Consello da Cultura Galega, 28 de febreiro de 2013.

Bouza-Brey Trillo, Fermín (1992): Artigos rosalianos. Santiago de Compostela: Xunta de Galicia.

Carballo Calero, Ricardo (1979): Estudos rosalianos: aspectos da vida e da obra de Rosalía de Castro. Vigo: Galaxia.

Carré Aldao, Uxío (1926-1927): “Estudio bio-bibliográfico-crítico sobre Rosalía de Castro (su vida y su obra)", Boletín de la Real Academia Gallega [publicado en entregas entre os números] 183 (01/06/1926) e $194(01 / 05 / 1927)$.

González Besada, Augusto (ca. 1916): Rosalía Castro. Notas biográficas. Madrid: Biblioteca Hispania.

March, Kathleen (2012): “Serían as súas verbas ou as súas vestimentas? Literatas de ambas as dúas orelas do Atlántico", Grial. Revista galega de cultura 194 (Número monográfico Novas olladas sobre Rosalía de Castro, eds. M a do C. Rábade e D. Vilavedra), pp. 34-41.

Pociña, Andrés e Aurora López (1991-1993): Rosalía de Castro: Documentación biográfica y bibliográfica crítica. A Coruña: Fundación Pedro Barrié de la Maza, 3 vols.

Pociña, Andrés (2001): “Avances da investigación sobre Rosalía nos anos 1991-1999”, en D. Kremer (ed.), Actas do VI Congreso Internacional de Estudios Galegos: un século de estudios galegos, Galicia fóra de Galicia (Universidad de La Habana, Facultad de Artes y Letras, Cátedra de Cultura Gallega, 17 a 21 de abril de 2000). Trier / Sada: Galicien-Zentrum der Universität Trier / Edicións do Castro.

Ribao Pereira, Montserrat (2012): “A biblioteca de La hija del mar”, Grial. Revista galega de cultura 194 (Número monográfico Novas olladas sobre Rosalía de Castro, eds. $\mathrm{M}^{\mathrm{a}}$ do Cebreiro Rábade e D. Vilavedra), pp. 42-47.

Rodríguez, Francisco (2011): Rosalía de Castro, estranxeira na súa patria. A persoa e a obra de onte a hoxe. A Coruña: Asociación Socio-Pedagóxica Galega.

Sanmartín Rei, Goretti (2013): "Usos e ideas sobre a lingua na obra de Rosalía". Intervención na mesa redonda do Congreso Rosalía de Castro no século XXI. Unha nova ollada. Santiago de Compostela: Consello da Cultura Galega, 28 de febreiro de 2013. 